\title{
Mechanical Behavior of New Composite Materials Reinforced by Waste Glass Fibre
}

\author{
Emilia Sabău ${ }^{1, a}$, Nicolae Bâlc ${ }^{1, b}$, Paul Bere ${ }^{1, c}$ \\ ${ }^{1}$ Technical University of Cluj-Napoca, Machine Building Faculty, Department of Manufacturing \\ Engineering, B-dul Muncii no. 103 -105, 400641, Cluj-Napoca, Romania \\ aEmilia.Sabau@tcm.utcluj.ro (corresponding author), bicolae.Balc@tcm.utcluj.ro, \\ cPaul.BERE@tcm.utcluj.ro
}

Keywords: composite materials, recycling, glass fibre, polyester resin, waste composites.

\begin{abstract}
In this paper the authors propose a new material which includes waste composites reinforced with glass fibres, sand and polyester matrix. Through a new manufacturing method were obtained composites plaques. The experimental tests of compressive strength to the material were presented. Also, the authors presented a study of reinforcement degree.
\end{abstract}

\section{Introduction}

Composite materials consist of a matrix (polyester resin, epoxy resin, and so on) which is reinforced with fiberglass, carbon, Kevlar, etc. Fibres glass are the most used reinforcing materials. They have many characteristics: high tensile strength, high chemical resistance, low cost. Fibre composites are increasingly used in the automotive and aeronautic industries, aero-spatial industry, constructions, sports equipment and medical devices, due to excellent properties $[1,2,3,4,5]$.

The storage and the recovery of waste composite materials is a problem we face today. The waste composite resulting from production processes and composite parts out of use occupy significant spaces for storage, Fig. 1. In time the accumulation of such materials can create serious problems to the manufacturing companies.

The provenance of waste, scraps or sub-products can be: from the basic flow technology; from current operations, which can be identified, selected, recovered, reconditioned and used by the operator which producing them; from basic technological process, but arising from annex operations (start, stop, cleaning, equipment adjustment and process); from objects that have completed the life cycle, end of life products, scraps with complex structure.

The recovery and recycling of polymeric composite materials has experienced an important concern in the last years. Researches dedicated to technologies for recycling composite materials were initiated and carried out by different authors $[6,7,8]$. Also, a recycle method of GFRP is investigated by [9].

It is known mixtures of concrete with sand and waste fiberglass [10,11,12]. Waste composites can be used for concrete reinforcement or for a variety of construction materials. Disadvantages of technical solutions known are that these materials have lower mechanical properties of the proposed material, high density, it's depreciates in time under the influence of external factors: moisture, sunlight, UV radiation.

Giraldi et al. [13] carried out recycled PET reinforced with glass fibre and Bartl et al. [14] has investigated product recycling of fibres obtained from tires. Vilaseca et al. [15] treat in their research recycled Kraft fibres (recycled softwood fibres) that coming from old sacs, used as reinforcement for the preparation of polypropylene composites.

Hugo et al. [16] were investigated recycled polymers with a range of different fillers, and developed applications that use waste thermoplastic polymer.

Reinforced materials and manufacturing procedures have a significant influence on the quality, productivity and competitiveness of composite structures. The interface between matrix-reinforced materials plays an essential part in the mechanical behavior and fabrication of composite materials. 
Waste composites were divided into short fibers and resin fragments by milling. Grinding waste reinforced composite material obtain a material with fiber glass reinforcement that is embedded in a mixture with an auxiliary material and a polyester matrix. The resulting material is a solid material having high mechanical characteristics.

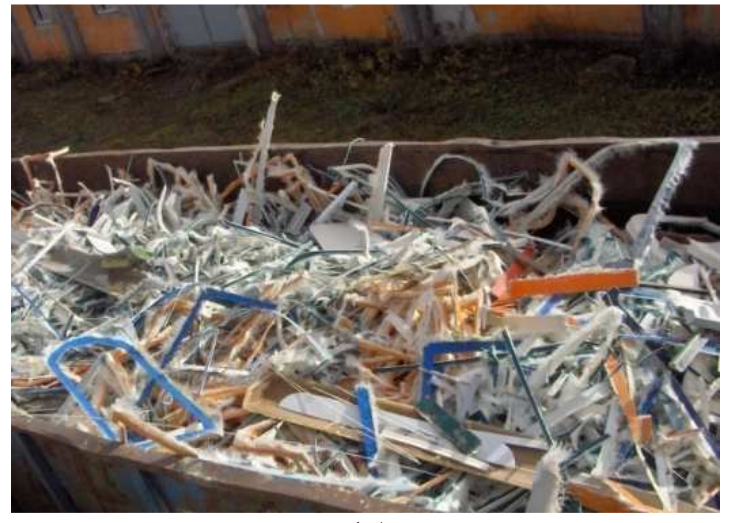

(a)

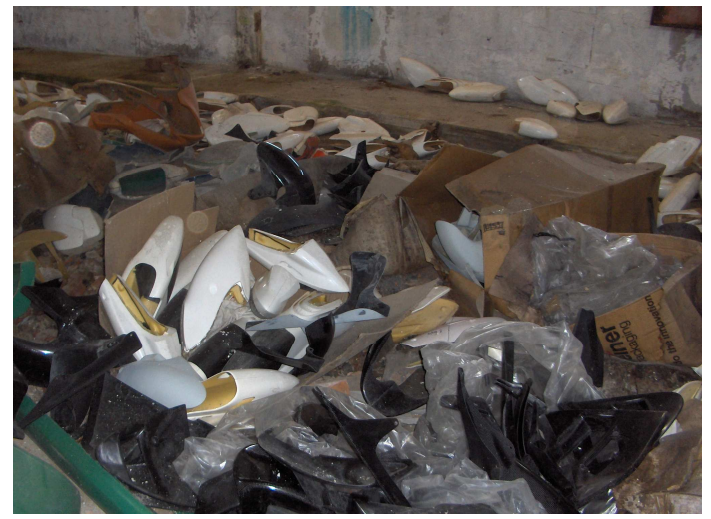

(b)

Fig. 1. Waste composites

All these researches make a significant contribution to the environment, and economic development in composite domain. Research results are expected to be disseminated to industry, especially for small and medium enterprises.

In this article composite plates that involve in the structure waste glass fibre were developed. Specimens were carried out to determine the physical and mechanical characteristics at compressive strengths. It was also performed a study on the microstructure of specimens required.

\section{Recycling fiber reinforced composite materials}

Waste reduction is an important aspect of pollution prevention for the environment. The authors propose to be used techniques of integration process of waste composite.

A solution regarding the recycling of waste composite materials is grinding of these materials (Fig. 2) and creating products that are embedded.

Grinding these waste materials we obtain a material rich in fiber glass that constitutes a very valuable reinforcement material. This could be embedded in another material or used in purpose to obtain reinforced composite materials.

Composite material after grinding was embedded in a mixture of sand and polymer matrix. In this case we used sand with a grain size of $0,3 \mathrm{~mm}$, Fig. 3 . Thus, a polymeric material was realized based on sand, waste glass fibre and polyester matrix. From this material were made cubic specimens with $50 \mathrm{~mm}$ side.

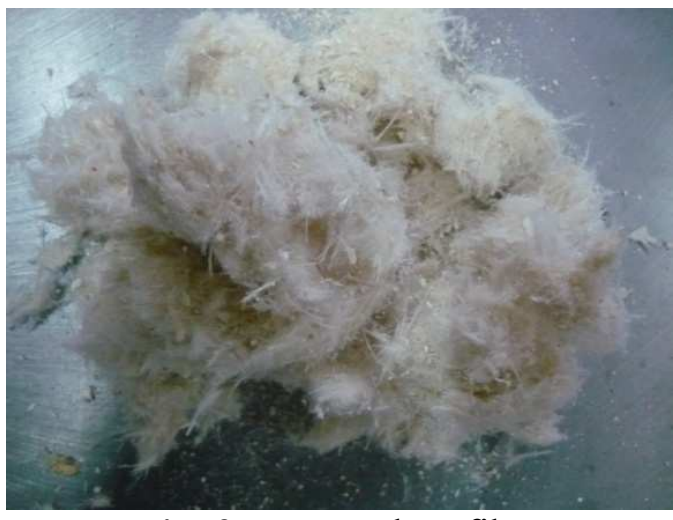

Fig. 2. Waste glass fiber

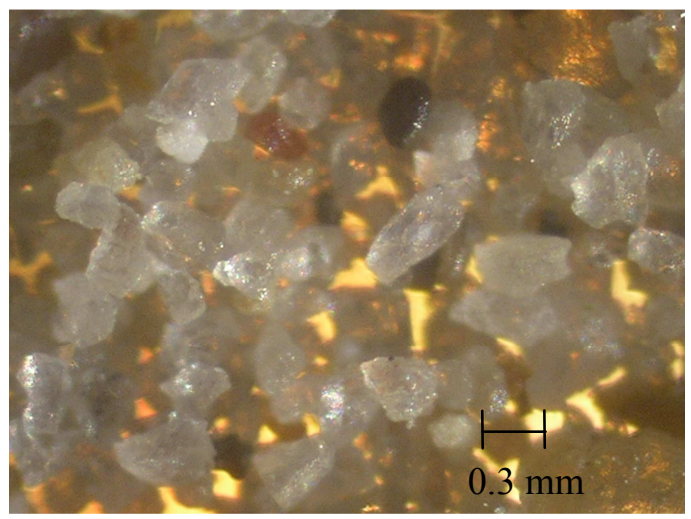

Fig. 3. Sand - reinforcement degree 
The parts obtained through recycling have a high mechanical value, so their areas of use can be multiple. For example, molds construction, construction of room separating walls, panels for shading and for rain, wind and snow protection on highways, thermal insulation of buildings, and so on.

\section{Microscopy study}

The microstructure of fracture samples from waste glass fibres /polyester matrix/sand composites was investigated using a metallographic microscope type Optika XDS-3 MET.

Fig. 4 shows impregnated monofilaments, where the particles of polyester resin are glued on the glass monofilaments.

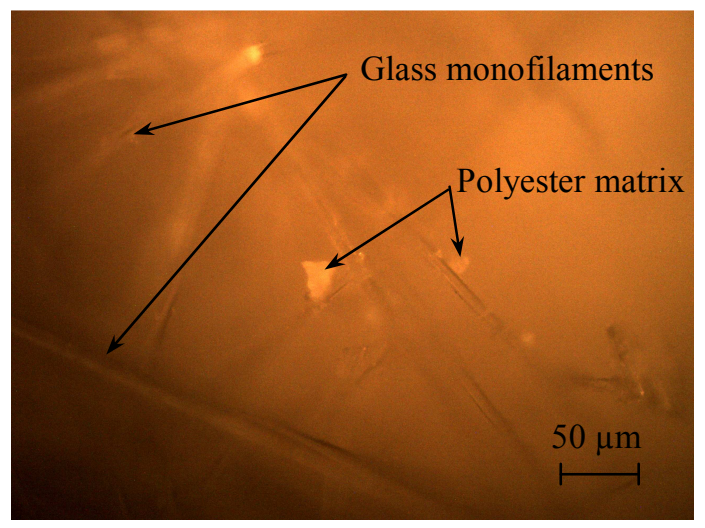

(a)

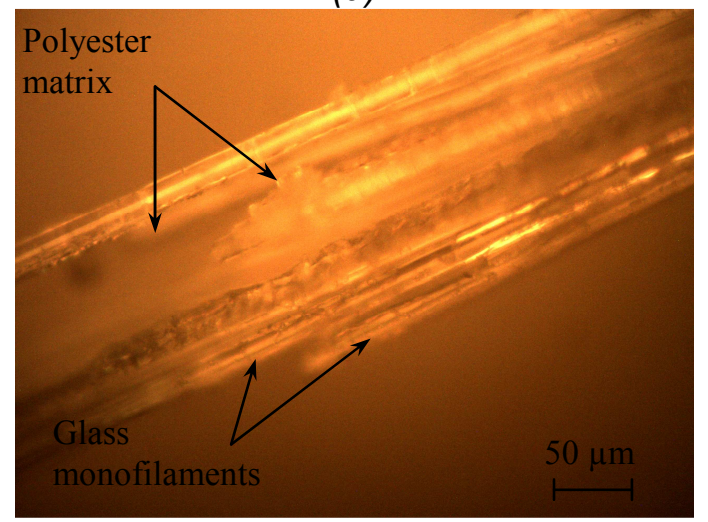

(c)

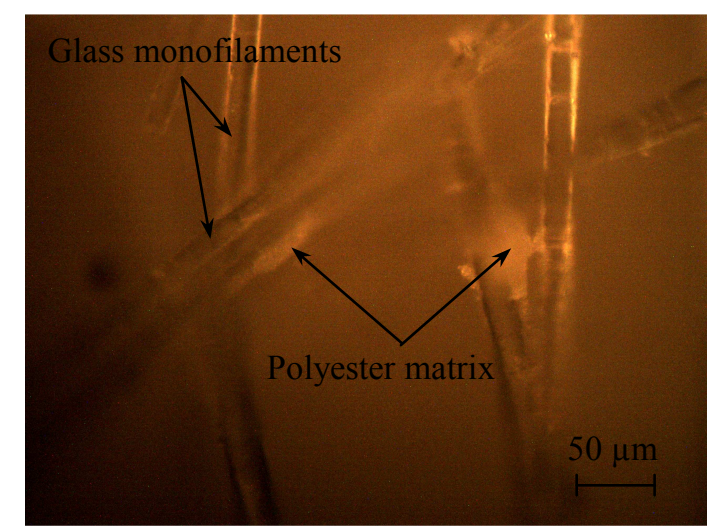

(b)

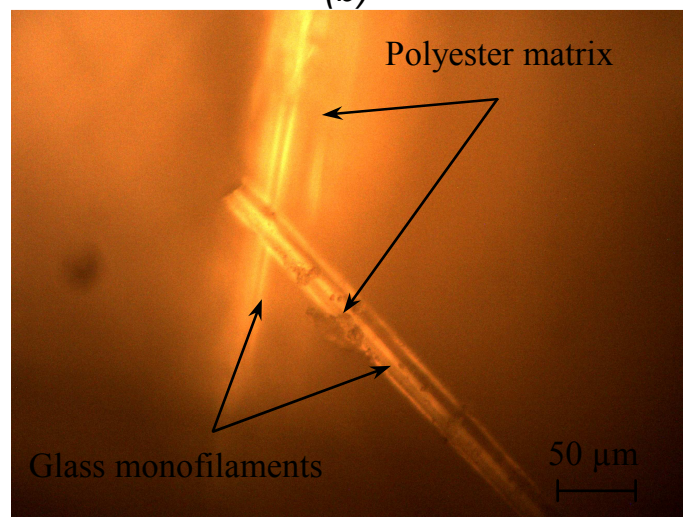

(d)

Fig. 4. Waste glass fibre - impregnated monofilaments

The analysis of fracture area morphology from waste glass fibres /polyester matrix/sand samples indicate monofilaments of glass fibre, simultaneously grouped and broken and the breaking area of the polyester matrix, Fig. 5.
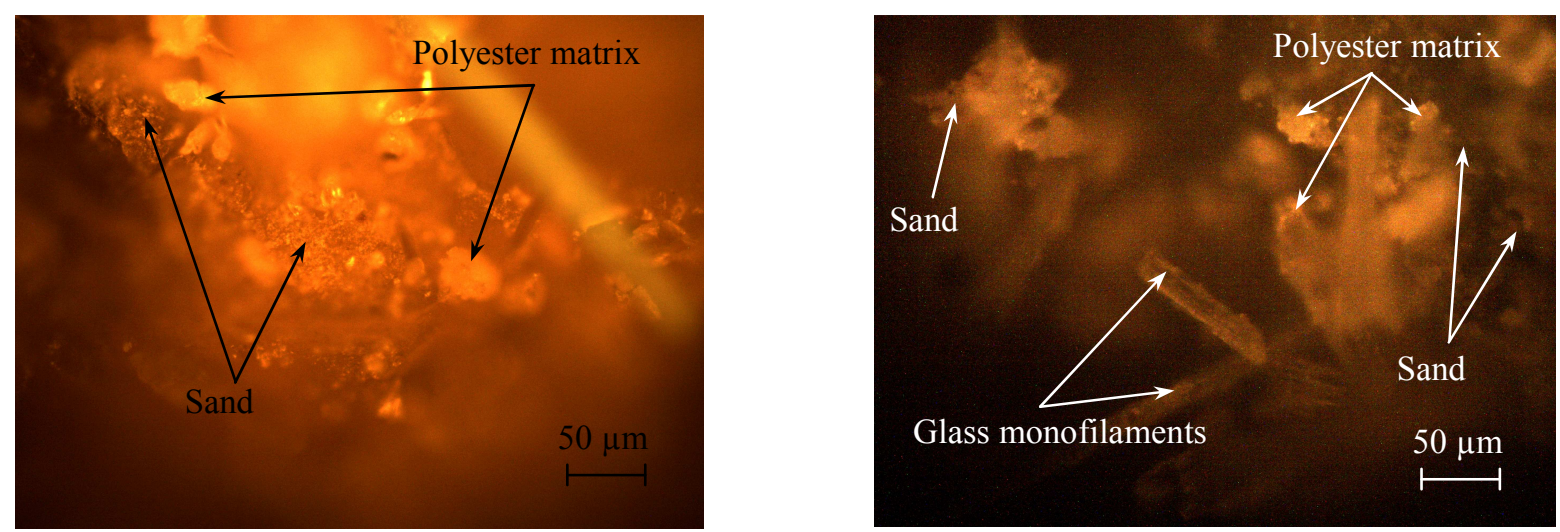

Fig. 5. The breaking area of the samples 
It appears a good impregnation of the matrix and a good compatibility between filaments, sand and matrix.

The particles of polyester resin and sand glued on the glass monofilament indicate that connection between glass fibres, sand and polyester matrix was correct.

A composite material with high mechanical properties and low density was achieved. These materials are able to reuse waste glass fibers.

\section{Experimental section}

In frame of this researches were elaborated composite plates that embedded into the structure waste composites. Theoretical calculations were made regarding the mechanical characteristics of the elaborated plates and were made samples to determine the physical and mechanical characteristics at compression tests.

The materials used in this study are waste glass fibres, sand granulation of $0,3 \mathrm{~mm}$ and polyester resin.

Polyester resin was used as matrix. The type and the characteristics of this material are: Polyester resin type Norpol 440-M750 (USA) is ortophtalic with low styrene emission, tixotropized and preaccelerated.

Technical characteristics of the resin are: Color: Transparent blue; Brookfield viscosity: 250-350 mPas; Time for obtaining jelly with $2 \%$ peroxide of MEEC: 8-15 min; Exothermic peak: 160-190 ${ }^{\circ} \mathrm{C}$; Exothermic peak time: 15-23 min.

Physical-Mechanical characteristics: Break strength: $62 \mathrm{MPa}$; Elongation at break: $2 \%$; Bending strength: $126 \mathrm{MPa}$; Impact resistance: $6,1 \mathrm{~mJ} / \mathrm{mm}^{2}$; Distortion temp. when exposed to heat: $72{ }^{\circ} \mathrm{C}$. In this case we used sand with a grain size of $0,3 \mathrm{~mm}$.

Quantities of materials components were as follows: $50 \%$ sand, $40 \%$ reinforcement material, $10 \%$ matrix. The material density was of $2200 \mathrm{~kg} / \mathrm{m}^{3}$.

\section{Calculation of reinforcement degree}

The mechanical characteristics of a composite material are determined also by the ratio between matrix and reinforcement material. This proportion can be expressed either by volume percentage or by mass percentage $[17,18,19]$. The mass percentages are easier to be determined at materials development, while the volume percentages occur directly in theoretical models that describe the composite materials behavior.

The relations are established for a material composed from two constituents, but these can be completed for materials composed of several constituents.

\section{* The mass percentage}

The mass percentage of fibres $M_{f}$ and mass percentage of matrix $M_{m}$ is calculated by the following relations:

$$
M_{f}=\frac{m_{f}}{m_{c}}, \quad M_{m}=\frac{m_{m}}{m_{c}} .
$$

where: $m_{f}$ - fibre mass; $m_{m}$ - matrix mass; $m_{c}$ - composite mass. Thus, from Eq. 1 we obtain the following expression:

$$
m_{f}+m_{m}=m_{c}
$$




\section{The volume percentage}

The volume percentage of fibers $V_{f}$ and volume percentage of matrix $V_{m}$ is calculated by the following relations:

$$
V_{f}=\frac{v_{f}}{v_{c}}, \quad V_{m}=\frac{v_{m}}{v_{c}}
$$

where: $v_{f}$ - fiber volume; $v_{m}$ - matrix volume; $v_{c}-$ composite volume. Adding the above relations we obtain:

$$
V_{f}+V_{m}=1 \quad \text { or } \quad V_{m}=1-V_{f} .
$$

The mass percentage $M_{f}$ or volume $V_{f}$ of fibres is called the ,reinforcement degree" of the composite structure.

\section{* Relations between mass percentage and volume percentage}

The relations between mass and volume percentages make to involve the composite material densities and its constituents. Masses and volumes are related by the following relations:

$$
m_{c}=\rho_{c} v_{c}, m_{f}=\rho_{f} v_{f}, m_{m}=\rho_{m} v_{m}
$$

where: $\rho_{c}$ - composite density; $\rho_{m}$ - density matrix; $\rho_{f}$ - fibre density. Taking into account the Eq. 2 results:

$$
\rho_{c}=\rho_{f} V_{f}+\rho_{m}\left(1-V_{f}\right)
$$

If we write the total composite volume:

$$
v_{c}=v_{f}+v_{m} .
$$

obtain from Eq. 5:

$$
\frac{m_{c}}{\rho_{c}}=\frac{m_{f}}{\rho_{f}}+\frac{m_{m}}{\rho_{m}}
$$

where express $\rho_{c}$ in function of mass percentage:

$$
\rho_{c}=\frac{1}{\frac{M_{f}}{\rho_{f}}+\frac{M_{m}}{\rho_{m}}} .
$$

Starting from the relations of definition, we obtain relations between the mass and volume percentage:

$$
M_{f}=\frac{\rho_{f}}{\rho_{c}} V_{f} \text { and } M_{m}=\frac{\rho_{m}}{\rho_{c}} V m
$$


Analogue, inverse relations are determined:

$$
V_{f}=\frac{\rho_{c}}{\rho_{f}} M_{f} \text { and } V_{m}=\frac{\rho_{c}}{\rho_{m}} M_{m}
$$

Using the above relations for new material recipes that embedded in the structure waste composite materials, in frame of the researches has varied the generally reinforcement degree (waste glass fibers and sand) and also the reinforcement degree based on fibers, and based on particles respectively.

\section{* Porosities presence in the composite}

The mixture of reinforcement material-matrix includes a certain amount of holes (gaps) called porosities. In fact we have:

$$
\begin{aligned}
& v_{f}+v_{m}+v_{p}=v_{c} \mid: v_{c} . \\
& V_{f}+V_{m}+V_{p}=1 .
\end{aligned}
$$

where: $V_{p}$ - pore volume percentage. The difference between the calculated density $\rho_{c t}$ with Eq. 9 and experimentally determined density $\rho_{c e}$ allows estimating the pore volume percentage $V_{p}$, by the expression:

$$
V_{p}=\frac{\rho_{c t}-\rho_{c e}}{\rho_{c t}}
$$

The presence of porosity in the composite material lead to a significant reduction of mechanical properties and increases the sensitivity of the composite material at environmental action: increase moisture absorption and decreases resistance to chemicals. It is therefore important to have a more precise estimate of the porosity volume percentage, thus assessing as accurately the composite material quality.

A quality composite material contains less than $1 \%$ porosities in volume, while a mediocre composite material containing up to $5 \%$ porosities. That's why, it is very important the chosen technological process for manufacturing composite material.

\section{Compressive tests composites}

From obtained previously material five specimens were made. These have 50x50x50 mm cubic dimensions according to EN 12320-3. Compressive specimens were required. The plates used during the experiments and the tests were performed in the Laboratory of the Technical University of Cluj-Napoca.

The testing machine used was Instron 1196, which has a $25 \mathrm{kN}$ load capacity. Test speed was of $2 \mathrm{~mm} / \mathrm{min}$ on compressive tests. The compressive tests were achieved at ambient temperature of $20^{\circ} \mathrm{C}$.

For determining the compressive breaking strength $\left(\sigma_{r c}\right)$ has been reported the maximum force at sectional aria required, using the relation:

$$
\sigma_{r c}=\frac{F_{\max }}{A}[\mathrm{MPa}]
$$


where: $F_{\max }$ - maximum compressive load to the specimen fracture, $[\mathrm{N}] ; A$ - initial cross-sectional area of the specimen, $\left[\mathrm{mm}^{2}\right]$.

Table 1. Compressive tests results

\begin{tabular}{|c|c|c|c|c|}
\hline No. & Force & $\begin{array}{c}\text { Average } \\
\text { force }\end{array}$ & $\begin{array}{c}\text { Average } \\
\text { compressive } \\
\text { breaking strength } \\
{[\mathrm{MN}]}\end{array}$ & Density \\
\cline { 1 - 2 }$[$. & 183,6 & & & \\
\cline { 1 - 2 } 2. & 189 & \multirow{K}{*}{187,58} & 75,03 & 1310 \\
\hline 3. & 195 & & & \\
\hline 4. & 178,3 & & & \\
\cline { 1 - 2 } 5. & 192 & & \\
\hline
\end{tabular}

The obtained results are presented in Table 1. Following the compressive stress of cubic specimens, the constituent composite material remains linked through filaments of reinforcement material. It wasn't found a violent depreciation of its.

\section{Summary}

The storage and the recovery of waste composite materials is a problem we face today. The waste composite resulting from production processes and composite parts out of use occupy significant spaces for storage. In time the accumulation of such materials can create serious problems to the manufacturing companies.

A solution regarding the recycling of waste composite materials is grinding of these materials and creating products that are embedded.

In this article a polymeric material was realized based on sand, waste glass fibre and polyester matrix. The manufacturing technologies used are: hand lay-up and compression processes. The experiments consist in compressive tests. From this material were made cubic specimens to determine the physical and mechanical characteristics at compressive strengths. Following the compressive stress of cubic specimens, the constituent composite material remains linked through filaments of reinforcement material.

It was also performed a study on the microstructure of specimens required. The analysis of fracture area morphology from waste glass fibres /polyester matrix/sand samples indicate monofilaments of glass fibre, simultaneously grouped and broken and the breaking area of the polyester matrix.

It appears a good impregnation of the matrix and a good compatibility between filaments, sand and matrix. The particles of polyester resin and sand glued on the glass monofilament indicate that connection between glass fibres, sand and polyester matrix was correct.

\section{Acknowledgment}

This paper was supported by the project "Development and support of multidisciplinary postdoctoral programmes in major technical areas of national strategy of Research - Development Innovation" 4D-POSTDOC, contract no. POSDRU/89/1.5/S/52603, project co-funded by the European Social Fund through Sectoral Operational Programme Human Resources Development 2007-2013. 


\section{References}

[1] D. Gay, S.V. Hoa, Composite Materials: Design and Applications, second ed., Boca Raton: CRC Press, 2007.

[2] E. J. Barbero, Introduction to composite materials design, second ed., CRC Press Taylor \& Francis Group, USA, 2010.

[3] L. P. Kollár, G. S. Springer, Mechanics of composite structures, Cambridge University Press, USA, 2003.

[4] V.V. Vasiliev, E.V. Morozov, Mechanics and analysis of composite materials, London: Elsevier Science, 2001.

[5] L. Shaofan, W. Gang, Introduction to micromechanics and nanomechanics, World Scientific Pub., 2008.

[6] S.J. Pickering, Recycling technologies for thermoset composite materials-current status, Composites: Part A. 37 (2006)1206-1215.

[7] T.A. Turner, S.J. Pickering, N.A. Warrior, Development of recycled carbon fibre moulding compounds - Preparation of waste composites, Composites: Part B. 42 (2011) 517-525.

[8] A. Bartl, A. Hackl, B. Mihalyi, M. Wistuba and I. Marini, Recycling of fibre materials, Institution of Chemical Engineers, Trans IChemE, Part B, Process Safety and Environmental Protection. 83(B4) (2005) 351-358.

[9] Y. Aono, S. Murae, T. Kubo, Static mechanical properties of GFRP laminates with waste GFRP interleaf, Procedia Engineering. 10 (2011) 2080-2085.

[10] N. Sebaibi, M. Benzerzour, N. E. Abriak, C. Binetruy, Mechanical properties of concretereinforced fibres and powders with crushed thermoset composites: The influence of fibre/matrix interaction, Construction and Building Materials. 29 (2012) 332-338.

[11] V.W.Y. Tam, X.F. Gao, C.M. Tam, K.M. Ng, Physio-chemical reactions in recycle aggregate concrete, Journal of Hazardous Materials. 163 (2009) 823-828.

[12] S. B. Park, B. C. Lee, J. H. Kim, Studies on mechanical properties of concrete containing waste glass aggregate, Cement and Concrete Research. 34 (2004) 2181-2189.

[13] A.L.F. de M. Giraldi, J.R. Bartoli, J.I. Velasco, L.H.I. Mei, Glass fibre recycled poly(ethylene terephthalate) composites: mechanical and thermal properties, Polymer Testing. 24 (2005) 507-512.

[14] A. Bartl, B. Mihalyi, I. Marini, Applications of renewable fibrous materials, Chemical Biochem Engineering. 18 (2004) 21-28.

[15] F. Vilaseca, J.A. Mendez, J.P. Lopez, M.E. Vallejos, L. Barbera, M.A. Pelach, X Turon, P. Mutje, Recovered and recycled Kraft fibres as reinforcement of PP composites, Chemical Engineering Journal. 138 (2008) 586-595.

[16] A.M. Hugo, L. Scelsi, A. Hodzic, F.R. Jones, R. Dwyer-Joyce, Development of recycled polymer composites for structural applications, Plast. Rubber Compos. 40(6-7) (2011) 323317.

[17] G. Zgură, V. Moga, Basis of composite materials design, Bren ed., Bucharest, 1999.

[18] M. Şomotecan, Composites. Resistance calculation., U.T. Pres ed., Cluj-Napoca, 2000.

[19] H. Iancău, O. Nemeş, Composite materiales. Design and manufacturing., Mediamira ed., ClujNapoca, 2003. 